\title{
How Old IS TOO OLd?: THE NEED FOR FEDERAL REGULATION IMPOSING A MAXIMUM AGE LIMIT ON WOMEN SEEKING INFERTILITY TREATMENTS
}

\author{
Melissa Reynolds*
}

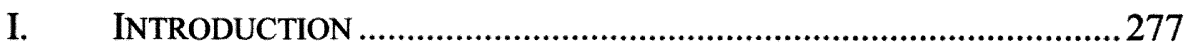

A. Infertility Technologies-Generally........................................280

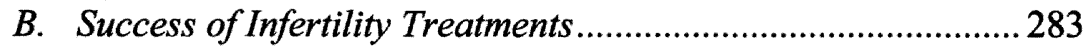

II. WHY INFERTILITY TREATMENTS SHOULD NOT BE UTILIZED BY

WOMEN OF ADVANCED-AGE ......................................................284

A. Decrease in Egg Quality and Reproductive Organ Health Associated with Increasing Age ................................................284

B. Risks to Both the Child \& the Mother ........................................285

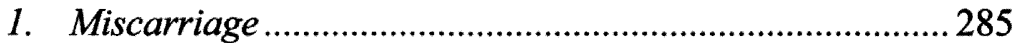

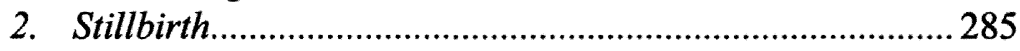

3. Premature Birth and Low Birth Weight ........................... 286

4. Chromosomal Abnormalities.............................................287

5. Pregnancy-Related Dangers ...............................................28

III. CURRENT STATE OF REGULATION IN THE UNITED STATES ............290

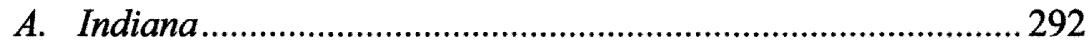

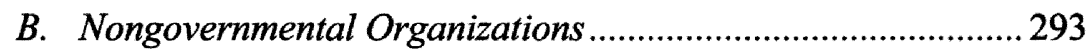

IV. FEDERAL REGULATION IS NEEDED IN THE UNITED STATES ............294

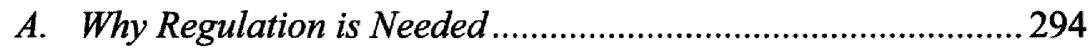

B. Substantive Due Process Framework ....................................298

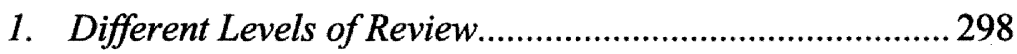

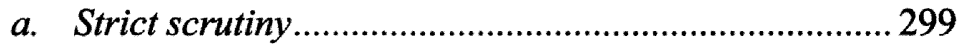

b. Intermediate Scrutiny...................................................299

c. Rational Basis ...............................................................299

d. Which Standard of Review Applies.............................. 299

2. Governmental Interests Advanced by Restricting Access to Infertility Treatments Based Upon Age .............................. 301

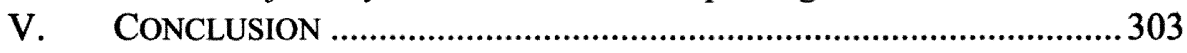

\section{INTRODUCTION}

In January 2005, Adriana Iliescu gave birth in Romania at the age of sixty-six. ${ }^{1}$ Iliescu underwent in-vitro fertilization using both egg and sperm

* J.D. Candidate, 2010, Indiana University School of Law-Indianapolis; B.S., 2007, Indiana University.

1. The Associated Press, Romanian woman, 66, gives birth to baby girl; Doctors say she is the world's oldest mother ever recorded, Jan. 17, 2005, http://www.msnbc.msn.com/ id/6835044/ (last visited March 13, 2009) [hereinafter AP, Romanian woman]. 
from anonymous donors. ${ }^{2}$ Iliescu was initially pregnant with triplets, but one of the fetuses was lost after nine weeks and another baby was stillborn. ${ }^{3}$ At that time, Iliescu was believed to have been the world's oldest woman to give birth. ${ }^{4}$

At the age of sixty, Frieda Birnbaum gave birth to twins in May of $2008^{5}$ Birnbaum was already the mother of three children - ages six, twenty-nine, and thirty-three. ${ }^{6}$ Birnbaum and her husband stated they wished to have another child in order for their six-year-old to have a sibling close to his age, and also "to remove some of the stigma attached to older women giving birth."7

Omkari Panwar, at the age of seventy, underwent infertility treatments in the hopes of conceiving a boy after having two daughters and five granddaughters. ${ }^{8}$ Panwar gave birth to twins, a boy and a girl, in India in July 2008. Also in India, approximately four months after Panwar gave birth, Rajo Devi and her husband, ages seventy and seventy-two, respectively, welcomed a baby girl born two months prematurely. ${ }^{9}$ Devi, who had undergone menopause twenty years prior, conceived with the help of a donor egg and IVF. ${ }^{10}$

Along with the advent and wide-spread usage of infertility treatments has come an increase in the use of such technology by older women. Before infertility treatments were available, a post-menopausal woman had no chance of conceiving and giving birth. The once impossible, however, is now possible-infertility treatments allow a woman past the age of menopause to carry and give birth to a child. Today, the news is full of stories of women in their fifties, sixties, or even seventies, giving birth to children with the assistance of reproductive technologies. "In the [United States], between 1980 and 2004, the proportion of all births increased ... nearly [four]-fold in women aged" forty years, and "first births [for this age group] increased [fifteen]-fold." ${ }^{11}$ Studies have suggested that since 1997, there

2. Id.

3. Id.

4. Id.

5. The Associated Press, Sixty-year-old N.J. woman delivers twins; Believed to be the oldest mom in U.S. to give birth to multiples, May 24, 2007, http://www.msnbc.msn.com/ id/18817248/ (last visited March 13, 2009) [hereinafter AP, N.J. woman].

6. Id.

7. Id.

8. Arthur Caplan Ph.D., New IVF dilemmas make old fears seem quaint; Twins for a 70-year-old? Louise Brown's doctors didn't envision this, July 24, 2008, http:// www.msnbc.msn.com/id/25837220/ (last visited March 13, 2009).

9. Lisa Belkin, The New York Times, 70-Year-Old Woman Gives Birth, Dec. 9, 2008, http://parenting.blogs.nytimes.com/2008/12/09/pregnant-at-70/?scp=4\&sq=birth\&st=cse (last visited March 13, 2009).

10. Id.

11. Barbara Luke \& Morton B. Brown, Elevated risks of pregnancy complications and adverse outcomes with increasing maternal age, 22 HUMAN REPRODUCTION, 1264, 1264, Feb. 8, 2007, available at http://humrep.oxfordjournals.org/cgi/content/full/del522vl (last 
has been an average increase of fourteen percent per year in births to women fifty years of age and older. ${ }^{12}$ An ever increasing number of women are deciding to postpone starting a family for a variety of reasons. Many women are choosing to first pursue advanced degrees, while others are waiting until after they have developed and settled into their careers to start a family. Additionally, many of these older women are now able to take advantage of recent technology, not available in their younger years, that assists them in conceiving. ${ }^{13}$ Also, as previously discussed, some women are taking advantage of reproductive technology later in life for reasons such as having a child of one sex or the other. ${ }^{14}$ Whatever the reason, many of these women are forced to turn to infertility treatments, as a woman's fertility declines with age.

Currently, the average age of menopause in the United States is fiftyone ${ }^{15}$ but the age range is age forty-five to age fifty-five. ${ }^{16}$ Past the age of fifty, most pregnancies will require some type of assistance, whether it is in the form of fertility drugs, hormones, or donated eggs. ${ }^{17}$ The few women who continue to ovulate after the age of fifty, and are successful in conceiving, typically must take hormones. ${ }^{18}$ These hormones are essential in order to even maintain the pregnancy, as most of these women's bodies have ceased producing the hormones necessary to support a pregnancy. ${ }^{19}$ The use of reproductive technologies by post-menopausal women in the hopes of conceiving a child is troubling for many reasons.

This Note will discuss the utilization of infertility treatments by women of advanced age, and the problems associated with such use. Part I of this Note will discuss background information regarding the technology involved in treating infertility. Part II of this Note will discuss the problems involved with women of advanced age using infertility treatments, and will mention statistics associated with such advanced-age births will also be

visited March 13, 2009). The year 1997 is the first year that statistics involving births to women fifty years of age and older were available. $I d$. at 9 .

12. $I d$.

13. See American Society for Reproductive Medicine, Third Party Reproduction, A Guide for Patients (Sperm, egg, and embryo donation and surrogacy), available at http://www.asrm.org/Patients/patientbooklets/thirdparty.pdf (last visited Feb. 14, 2009) [hereinafter ASRM, Third Party Reproduction]. According to the American Society for Reproductive Medicine, the first pregnancy resulting from egg donation did not occur until 1984. Id. at 4.

14. See supra Part I. INTRODUCTION (discussing the case of Omkari Panwar).

15. COMmitTeE ON GyNeCOlogic Practice, THE AMERICAN COllege OF ObSTETRICIANS AND GYNeCOlOGISTS, COMMITTEE OPINION No. 413, Age-RELATED FERTILITY DECLINE, at 1 (2008), available at http://www.asrm.org/Media/Practice/AgeRelatedFertilityDecline.pdf (last visited Nov. 8, 2008) [hereinafter OPINION No. 413].

16. Laura F. McCarthy, Pregnancy at 20,30, 40; Is There a Perfect Time to Have a Baby?, BABYTALK, Dec. 2000/Jan. 2001, at 86, available at http://www.parenting.com/ pregnancy/article/pregnancy-at-20-30-40 (last visited April 4, 2010).
17. $I d$.
18. Id.
19. Id. 
mentioned. Part III of this Note will discuss the United States' current state of regulation in the area of reproductive technologies, both at the state and at the federal levels. Part IV of this Note will discuss the need for regulation in the area of assisted reproduction, as well as possible substantive due process issues. Although there may be a potential equal protection challenge to the federal regulation proposed in this Note, because it pertains to women alone, only the issues accompanied by advanced-age pregnancies for the mother and prospective child will be addressed.

While there are many areas within the field of assisted reproduction that potentially could be regulated, this Note focuses exclusively on the need for federal regulation imposing a maximum age limit on women seeking infertility treatments. Part V concludes that federal regulation imposing a maximum age limit on women seeking access to infertility treatments is necessary and is justified in light of the strong interests advanced by such regulation.

\section{A. Infertility Technologies-Generally}

Health care providers use the term "infertility" to describe:

women who are unable to get pregnant, and ... men who are unable to impregnate a woman, after at least one year of trying. In women, the term is used to describe those who are of normal childbearing age, not those who can't get pregnant because they are near or past menopause. Women who are able to get pregnant but who cannot carry a pregnancy to term (birth) may also be considered infertile. ${ }^{20}$

Consequently, a woman who cannot conceive due to the fact that she is past menopause is not really "infertile," as that term is used by those in the health care industry.

Infertility can be caused by many different individual factors, or a combination of factors, including environmental factors, genetic conditions, or health issues. ${ }^{21}$ There are a variety of procedures available for treating female infertility. Those procedures that involve the handling of both eggs and sperm are known as "assisted reproductive technologies" ("ART"). ${ }^{22}$

20. National Institute of Child Health and Human Development, Infertility/Fertility, What is Infertility?, http://www.nichd.nih.gov/health/topics/infertility_fertility.cfm (last visited Nov. 8, 2008).

21. Id.; See id. for a more thorough discussion of the potential causes of both female and male infertility.

22. Centers for Disease Control and Prevention, Department of Health and Human Services, What is Assisted Reproductive Technology (ART)?, http://www.cdc.gov/art (last 
According to Centers for Disease Control and Prevention,

ART procedures involve surgically removing eggs from a woman's ovaries, combining them with sperm in the laboratory, and returning them to the woman's body or donating them to another woman. They do NOT include treatments in which only sperm are handled (i.e., intrauterine - or artificial insemination) or procedures in which a woman takes medicine only to stimulate egg production without the intention of having eggs retrieved. ${ }^{23}$

In 2002, the American Society for Reproductive Medicine ("ASRM") determined that the use of ARTs resulted in the birth of almost one in every hundred babies born in the United States. ${ }^{24}$ Based upon reported births, between the years 1985 and 2006, the use of ARTs led to approximately 500,000 children born in the United States. ${ }^{25}$ Additionally, the 2006 ART Report, currently the most recent report published by the Centers for Disease Control, estimates that ten percent of all reported ART services were used by women over the age of forty-two. ${ }^{26}$ This number is up from four percent in $2005^{27}$

In 1981, IVF was introduced in the United States. ${ }^{28}$ IVF involves the surgical removal of eggs from a woman's ovary and then the combination of these eggs with sperm outside of the body. ${ }^{29}$ Thus, the actual fertilization process occurs outside of the woman's body. If these eggs are success-

visited Nov. 8, 2008) [hereinafter CDC, What is ART?].

23. Id.

24. American Society for Reproductive Medicine, Frequently Asked Questions About Infertility -Does In Vitro Fertilization Work?, http://www.asrm.org/Patients/faqs.html\#Q7: (last visited July 21, 2009).

25. $I d$.

26. Centers for Disease Control and Prevention, American Society for Reproductive Medicine, Society for Assisted Reproductive Technologies, 2006 Assisted Reproductive Technology Success Rates: National Summary and Fertility Clinic Reports, at 15 (2008), available at $\mathrm{http} / / / \mathrm{www} . c d c . g o v / a r t / A R T 2006 / 508 \mathrm{PDF} / 2006 \mathrm{ART}$.pdf (last visited April 4, 2010) [hereinafter CDC, 2006 ART Report]. The purpose of the annual ART report is to assist interested individuals in determining where to obtain treatment, as well as informing those individuals of a clinic's success rate. CDC, What is ART?, supra note 22.

27. Victoria C. Wright et al., Assisted Reproductive Technology Surveillance-United States, 2005, CENTERS FOR DISEASE CONTROL AND PREVENTION (JUNE 20, 2008), available at $\mathrm{http} / / / \mathrm{www} . \mathrm{cdc} . g o v / \mathrm{mmwr} / \mathrm{preview} / \mathrm{mmwrhtml} / \mathrm{ss} 5705 \mathrm{a} 1 . \mathrm{htm}$ ?s_cid=ss5705a1_e (last visited March 13, 2009); Fertility Clinic Success Rate and Certification Act of 1992, 42 U.S.C.A. § 263a-1 et seq. (West 1992).

28. American Society for Reproductive Medicine, Frequently Asked Questions About Infertility - Does In Vitro Fertilization Work?, http://www.asrm.org/Patients/faqs.html\#Q7: (last visited July 21,2009 ).

29. American Society for Reproductive Medicine, Frequently Asked Questions About Inftertility - What is In Vitro Fertilization?, http://www.asrm.org/detail.aspx?id=3022 (last visited April 4, 2010) [hereinafter ASRM, What is In Vitro Fertilization?]. 
fully fertilized and begin to divide, they are inserted into the woman's rus. $^{30}$

Once an egg has been fertilized, it is then referred to as an "embryo." IVF accounts for more than ninety-nine percent of all ART procedures performed in the United States. ${ }^{31}$ IVF, however, "accounts for less than five percent of all infertility treatment in the United States," because not all infertility treatments are considered "ART procedures." 32

Two other commonly used ART procedures exist. Zygote Intrafallopian Transfer ("ZIFT"), like IVF, the fertilization of the egg occurs outside of the woman's body. ${ }^{33}$ Once the eggs and sperm are combined and fertilization occurs, the embryos are inserted into a woman's fallopian tube. ${ }^{34}$ Gamete Intrafallopian Transfer ("GIFT") is the other commonly used ART procedure that differs from IVF in that the fertilization process occurs inside of the woman's body, as opposed to occurring outside the body, in a Petri dish. ${ }^{35}$ Eggs are retrieved from a woman's ovary, and then the eggs, with sperm, are immediately inserted into a woman's fallopian tubes. ${ }^{36}$ Only women with normal fallopian tubes may utilize GIFT. ${ }^{37}$

Yet another option is cryopreservation. A woman's eggs or a man's sperm can be preserved by freezing them for later use. Cryogenic technology also allows for an embryo to be frozen for later use. Cryopreservation involves the immersion of embryos, or eggs or sperm, in liquid nitrogen "between the time [the zygote] reache[s] the two-cell or eight-cell stage." ${ }^{38}$ Then, when the embryo, eggs, or sperm are needed, they are thawed and inserted into a woman's uterus during her menstrual cycle. ${ }^{39}$

Finally, there is artificial insemination. In artificial insemination, a physician uses a thin tube called a catheter to introduce sperm "directly into a woman's cervix, fallopian tubes, or uterus. This makes the trip shorter for the sperm and bypasses any possible obstructions." ${ }^{, 40}$ When the sperm is

30. $I d$.

31. CDC, 2006 ART Report, supra Note 26 at 89.

32. ASRM, What is In Vitro Fertilization?, supra note 29.

33. Society for Assisted Reproductive Technologies, Assisted Reproductive Technologies, http://www.sart.org/Guide_AssistedReproductiveTechnologies.html (last visited Nov. $8,2008)$.

34. $I d$.

35. $I d$

36. Id.

37. AMERICAN SOCIETY FOR REPRODUCTIVE MEdicine, ASSISTED REPRODUCTIVE TECHNOLOGIES: A GUIDE FOR PATIENTS 10 (2008) available at http:/www.asrm.org/Patients/ patientbooklets/ART.pdf (last visited Feb. 14, 2009) [hereinafter ASRM, ASSISTED REPRODUCTIVE TECHNOLOGIES].

38. Kimberly E. Diamond, Cryogenics, Frozen Embryos and the Need for New Means of Regulation: Why the U.S. is Frozen in its Current Approach, 11 N.Y. INT'L L. REV. 77, 78-79 (1998).

39. Id. at 79.

40. A Couples Guide: Trying to Conceive; Artificial Insemination, reviewed by Mikio A. Nihira, M.D., WebMD, http://www.webmd.com/infertility-and-reproduction/guide/artificial- 
placed in the woman's uterus, as opposed to the fallopian tubes or cervix, the procedure is called intrauterine insemination ("IUI").

\section{B. Success of Infertility Treatments}

By the age of thirty, a woman's fertility starts to decline, dropping significantly. at the age of thirty-eight. ${ }^{42}$ Since 1996, the Centers for Disease Control and Prevention ("CDC") has been collecting data via a webbased collection system regarding ART procedures performed in medical centers throughout the United States, as required by the Fertility Clinic Success Rate and Certification Act of 1992 ("FCSRCA"). ${ }^{43}$ This data collection system is called the National ART Surveillance System ("NASS"). According to the Assisted Reproductive Technology Surveillance, 134,260 ART procedures were performed in $2005 .{ }^{45}$ These procedures led to 38,910 live-birth deliveries, and 52,041 babies were born as a result. ${ }^{46}$ The higher number of babies born as compared to the number of deliveries is due to the birth of multiples. In 2005, according to reports, the average live-birth rate for ART procedures involving the use of a woman's own eggs was thirtyfour percent." ${ }^{47}$ This ART success rate decreased significantly "from [fortythree] percent among women [under the age of thirty-five] to [six] percent among women [over the age of forty-two]. ${ }^{, 48}$ According to the 2006 ART Report, for women over the age of forty-four who underwent ARTs using fresh non-donor eggs or embryos, the rate of live births was only approximately one percent. ${ }^{49}$

The success rate of IVF in women under the age of thirty-five is twenty-five to twenty-eight percent, and for women over the age of forty, the success rate significantly decreases to six to eight percent. ${ }^{50}$ In 2006 , the percentages of GIFT and ZIFT procedures resulting in live births that year were approximately twenty-four percent and almost eighteen percent, respectively. $^{51}$

insemination (last visited Nov. 8, 2008).

41. Id.

42. McCarthy, supra note 16.

43. Wright et al., supra note 27; Fertility Clinic Success Rate and Certification Act of 1992, 42 U.S.C.A. § 263a-1 et seq. (West 1992).

44. Wright et al., supra note 27.

45. Id.

46. Id.

47. Id.

48. Id.

49. CDC, 2006 ART Report, supra note 26, at 27.

50. McCarthy, supra note 16.

51. CDC, 2006 ART Report, supra note 26, at 40. 


\section{WHY INFERTILITY TREATMENTS SHOULD NOT BE UTILIZED BY WOMEN OF ADVANCED-AGE}

\section{A. Decrease in Egg Quality and Reproductive Organ Health Associated with Increasing Age}

Fertility-harming disorders, such as fibroids, endometriosis, and tubal disease, increase with age. ${ }^{52}$ Ovarian aging, meaning a decrease in egg quality, not quantity, appears to be one cause of the increasing risk of infertility as a woman ages. ${ }^{53}$ According to Benjamin Younger, M.D., Executive Director of the American Society of Reproductive Medicine, as a woman's eggs age, fertilizing them becomes difficult. ${ }^{54}$ In addition, as women age, there is "a significant increase in the rates of aneuploidy and spontaneous abortion." 55 The increased rates of aneuploidy and spontaneous abortion occur because, as a woman and her eggs age, her eggs "are more likely to have genetic abnormalities." Aneuploidy is defined as "[t]he occurrence of one or more extra or missing chromosomes leading to an unbalanced chromosome complement, or, any chromosome number that is not an exact multiple of the haploid number." 57 One specific form of aneuploidy causes of Down syndrome. Down syndrome can result from having three, as opposed to two, copies of the twenty-first chromosome. ${ }^{58}$ Trisomy occurs in approximately two percent of pregnancies among women under the age of twenty-five, and the risk increases to almost thirty-five percent among women over the age of forty. ${ }^{59}$ Down syndrome can also be caused when only some cells having an extra copy of the twenty-first chromosome, or "when part of the [twenty-first] chromosome becomes attached [translo-

52. OPINION No. 413 , supra note 15 , at 1 .

53. European Society of Human Reproduction and Embryology Workshop Group, Fertility and Ageing, 11 HUMAN REPRODUCTION UPDATE 261, 261 (2005), available at http://humupd.oxfordjournals.org/cgi/reprint/11/3/261? maxtoshow $=\& H I T S=10 \&$ hits $=10 \& R$ ESULTFORMAT=\&fulltext=fertility+and+ageing\&searchid=1\&FIRSTINDEX=0\&resource type $=$ HWCIT (last visited March 13, 2009).

54. McCarthy, supra note 16.

55. OPINION No. 413, supra note 52, at 1 (citing WW Newcomb, M Rodriguez, and JW Johnson, Reproduction in the Older Gravida. A Literature Review, 36 J. REPROD. MED. 839 (1991)).

56. AmERICAN SOCIETY for ReProductive MEDICINE, Age AND FERTILITY: A GuIDE FOR PATIENTS 6 (2003), available at http:/www.asrm.org/Patients/patientbooklets/ agefertility.pdf (last visited Feb. 14, 2009) [hereinafter ASRM, AGE AND FERTILITY].

57. U.S. National Library of Medicine, Genetics Home Reference, Aneuploidy, http://ghr.nlm.nih.gov/glossary=aneuploidy (last visited Jan. 7, 2009).

58. Mayo Clinic Staff, Down Syndrome Causes, MaYoClinic.COM, April 7, 2009, http://www.mayoclinic.com/health/down-syndrome/DS00182/DSECTION=causes (last visited April 4, 2010). [hereinafter Mayo Clinic, Down Syndrome Causes] 68.

59. European Society of Human Reproduction and Embryology, supra note 53, at $267-$ 
cated] onto another chromosome, before or at conception." ${ }^{60}$ Aside from these fertility-harming disorders, there are other more serious risks to the mother and child associated with a late-age pregnancy.

\section{B. Risks to Both the Child \& the Mother}

\section{Miscarriage}

According to studies, children born to women at the age of forty "were more likely to be premature, have low birthweight, and be admitted to in-

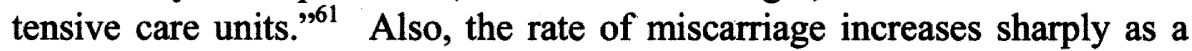
woman ages. For women aged thirty-three to thirty-four years, the rate of

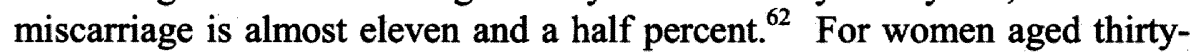
five to thirty-seven years, the miscarriage rate is thirteen and seven-tenths percent, and nineteen and eight-tenths percent for women aged thirty-eight to forty years. $^{63}$ In women aged forty-one to forty-two years and forty-two years and older, the miscarriage rate increases to almost thirty percent and over thirty-six and a half percent, respectively. ${ }^{64}$

The rate of miscarriage following IVF can be as high as fifty percent in women over the age of forty. ${ }^{65}$ In fact, according to the 2006 ART Report, fifty-six percent of women over the age of forty-three who utilized ARTs using fresh non-donor eggs or embryos suffered a miscarriage. ${ }^{66}$ Miscarriage is the end result in approximately one-third of all pregnancies occurring in women aged forty to forty-four years. ${ }^{67}$ Some reasons for such a high rate of miscarriage include defective eggs, inadequate uterine lining, or an inadequate blood supply to the uterus. ${ }^{68}$

\section{Stillbirth}

Another high risk associated with pregnancies of older women is the risk of a child born stillborn. Stillbirth is defined as "death of the fetus after [twenty] weeks of pregnancy."69 "The risk of stillbirth is doubled for wom-

60. Mayo Clinic, Down Syndrome Causes, supra note 58.

61. European Society of Human Reproduction and Embryology, supra note 53, at 273.

62. Id., at 2 .

63. Id.

64. Id.

65. Keith A. Byers, Infertility and In Vitro Fertilization: A Growing Need for Consumer-Oriented Regulation of the In Vitro Fertilization Industry, J. LEGAL MED. 18, 33 (1997).

66. CDC, 2006 ART Report, supra note 26, at 28.

67. McCarthy, supra note 16.

68. McCarthy, supra note 16.

69. March of Dimes, Pregnancy After 35, http:/www.marchofdimes.com/professionals/ 14332_ 1155.asp (last visited Jan. 15, 2009) [hereinafter Dimes, Pregnancy After 35]. 
en in their [forties], compared with those in their [twenties]."70 A real-life example of such risks was experienced by Adriana Iliescu, who was mentioned in the Introduction to this Note, as she lost two of the three fetuses she was carrying during her pregnancy. ${ }^{71}$

\section{Premature Birth and Low Birth Weight}

Delivery is considered to be "premature" if it occurs before thirtyseven weeks." "Women ages ... [forty] and older are more likely than women in their ... [twenties] and ... [thirties] to deliver prematurely (before... [thirty-seven] completed weeks of pregnancy)",73 Premature birth can be dangerous for the child. Children born prematurely have a higher risk of experiencing health problems immediately following birth, as well as long-term disabilities. ${ }^{74}$ A study conducted in 2006 found that babies born between thirty-four and thirty-six weeks "were more than three times as likely as full-term babies to be diagnosed with cerebral palsy and were also at increased risk for developmental delay or mental retardation." 75

Additionally, studies show the occurrence of low birth weight as well as very low birth weight increases with maternal age. ${ }^{76}$ Low birth-weight babies are at an increased risk for respiratory distress syndrome ("RDS"), intraventricular hemorrhage ("IVH"), patent ductus arteriorsus ("PDA"), necrotizing enterocolitis ("NEC"), and retinopathy of prematurity ("ROP")."

RDS is a breathing problem caused by a lack of surfactant, which keeps the air sacs in the lungs from collapsing. ${ }^{78}$ In order to keep a baby's lungs expanded, treatment with surfactant is necessary, as well as the administration of oxygen and mechanical breathing. ${ }^{79}$ IVH is bleeding in the brain, which, if severe, may cause pressure on the brain and lead to brain damage. ${ }^{80}$ In such severe cases, physicians must insert into the baby's brain a tube in order to drain the accumulated fluid. ${ }^{81}$ PDA occurs when the duc-

70. McCarthy, supra note 16.

71. See AP, Romanian woman, supra note 1.

72. Dimes, Pregnancy After 35, supra note 69.

73. Id.

74. Id.

75. Robert Preidt, Late Preterm Birth Poses Developmental Risks; Caesarean or induction should not be done before 39 weeks unless necessary, study says, MEDLINE PLUS, Dec. 11, 2008, http://www.nlm.nih.gov/medlineplus/news/fullstory_72696.html.

76. Luke \& Brown, supra note 11, at 1265-66.

77. March of Dimes, Low Birthweight: What medical problems are common in lowbirthweight babies?, http://www.marchofdimes.com/professionals/14332_1153.asp (last visited Jan. 16, 2009) [hereinafter Dimes, Low Birthweight].

78. $I d$.

79. $I d$.

80. Id.

81. Id. 
tus arteriosus, a large artery allowing the baby's blood to bypass its lungs while in the womb, fails to close, potentially leading to heart failure. ${ }^{82}$ In order to treat PDA, a drug is administered, and if this drug is ineffective, surgery is performed to correct the problem. ${ }^{83} \mathrm{NEC}$ is an intestinal problem that develops a few weeks after birth. ${ }^{84}$ Babies suffering from NEC are treated with antibiotics and fed intravenously until the baby's intestine has healed. ${ }^{85}$ Surgery to remove the damaged piece of intestine may be required in some cases. "ROP is an abnormal growth of blood vessels in the eye that can lead to vision loss." 87 Oftentimes, the condition is corrected without treatment, resulting in little or no vision loss. ${ }^{88}$ In severe cases, however, treatment of the abnormal blood vessels with laser therapy or cryotherapy may be necessary in order to preserve the baby's vision. ${ }^{89}$

In addition to suffering from serious conditions as newborns, some studies have suggested that babies born with a low birth weight "may be at increased risk for certain chronic conditions in adulthood," such as hypertension, Type II diabetes, and heart disease..$^{90}$

\section{Chromosomal Abnormalities}

As a woman ages, her likelihood of giving birth to a child suffering from Down syndrome increases. Again, Down syndrome is caused by a chromosomal anomaly, which occurs when the child is born with three, as opposed to two, copies of the twenty-first chromosome. A twenty-year-old woman has a 1 in 1,667 chance of giving birth to a baby born with Down syndrome, and a 1 in 526 chance of the baby having other chromosomal anomalies. ${ }^{91}$ Chromosomal anomalies can be the cause of many different birth defects, encompassing physical, developmental and mental disabilities. At the age of thirty, a woman's risk of having a child born with Down syndrome or some other chromosomal anomaly is 1 in 952 and 1 in 385, respectively. $^{92}$ These rates begin to increase significantly from the ages of thirty-five to thirty-nine, when the likelihood of Down syndrome and other chromosomal abnormalities increases to 1 in 378 and 1 in 192, respectively. ${ }^{93}$ A forty-year-old woman has a 1 in 106 chance that of giving birth to a

82. Dimes, Low Birthweight, supra note 77.

83. Id.

84. Id.

85. Id.

86. Id.

87. Dimes, Low Birthweight, supra note 77.

88. Id.

89. Id.

90. Id.

91. McCarthy, supra note 16.

92. McCarthy, supra note 16.

93. Id. 
child afflicted with Down syndrome and a 1 in 66 chance a child will have some type of chromosomal anomaly. ${ }^{94}$ By the age of forty-nine, a woman's chances of having a child born with Down syndrome or another chromosomal abnormality has increased to 1 in 11 and 1 in 8 , respectively. ${ }^{95}$ Thus, in only nine years, a woman's chance of giving birth to a child afflicted with Down syndrome rises from 1 in 106 to 1 in 11 . These statistics illustrate the likelihood of having a child born with some type of genetic abnormality increases drastically as a woman ages.

Today, there are available methods for screening embryos for genetic abnormalities before implantation of the embryo. One such method is called pre-implantation genetic diagnosis ("PGD"). ${ }^{96}$ PGD involves the taking of one cell from an eight-cell embryo to test for genetic abnormalities. ${ }^{97}$ If it is determined that the embryo is genetically "normal," the embryo will then be transferred into the woman. ${ }^{98}$ As of 2006 , approximately seventy-five percent of fertility clinics offered PGD. ${ }^{99}$ In a study involving eighty infertility patients with an average age of forty years old, sixty percent of the embryos screened using PGD were found to have chromosomal abnormalities. ${ }^{100}$ While PGD may help some prevent the use of genetically abnormal embryos that would lead to chromosomal anomalies in a child, this test is not always completely accurate because babies are nevertheless born with conditions for which the test was supposed to screen. ${ }^{101}$ Also, as discussed throughout this Note, there are many other dangers associated with advanced age pregnancies that have absolutely nothing to do with the genetic make-up of an embryo.

\section{Pregnancy-Related Dangers}

The results of a study conducted between 1995 and 2000 showed that "[i]ncreasing maternal age is associated with significantly elevated risks for pregnancy complications and adverse outcomes."102 According to other studies, women over the age of forty are more likely to suffer gestational diabetes, pregnancy-induced hypertensive disorders, and have instrumental deliveries and Caesarean sections than younger women. ${ }^{103}$

94. Id.

95. $I d$.

96. Rick Weiss, Increasingly, Couples Use Embryo Screening, THE WASHINGTON PosT, Sept. 21, 2006, at A02, available at http://www.washingtonpost.com/wpdyn/content/article/2006/09/20/AR2006092001652.html (last visited March 13, 2009).

97. Id.

98. Id.

99. Id.

100. Kate Johnson, Age At Issue in Aneuploidy Screening: Questions Raised about IVF Screening Practice, 39 Ов. GуN. News 20, 20, Sept. 1, 2004.

101. Weiss, supra note 96.

102. Luke \& Brown, supra note 11 , at 1264.

103. European Society of Human Reproduction and Embryology, supra note 53, at 273. 
Gestational diabetes is a form of diabetes that a woman develops only during pregnancy, and results in a higher likelihood of giving birth to a baby much larger than average. ${ }^{104} \mathrm{~A}$ large baby is at risk of injury during birth. ${ }^{105}$ According to studies, women over the age of thirty-five are approximately twice as likely to suffer from gestational diabetes as younger women. ${ }^{106}$ Additionally, during pregnancy, the likelihood of a woman suffering high blood pressure "is about double for women over [thirty-five] compared with younger women."

Another pregnancy-related danger that increases with age is placenta previa. Placenta previa is a condition in which the placenta covers all or part of the cervix. ${ }^{108}$ Women with this condition may hemorrhage during delivery, creating a danger for both mother and child. ${ }^{109}$ Studies show that women in their forties are approximately three times more likely to suffer placenta previa than younger women. ${ }^{110}$ The risk of placenta abruption, where "all or part of the placenta separates from the uterine wall," also increases in women of advanced age. ${ }^{111}$ Untreated placenta abruption can be life-threatening for both the mother and baby. ${ }^{12}$ Placenta abruption causes the unborn baby to be deprived of oxygen and nutrients, which may ultimately lead to neurological or behavioral problems, and causes severe bleeding in the mother. ${ }^{113}$ If the mother's bleeding cannot be controlled, a hysterectomy may be necessary. ${ }^{114}$

Studies have also shown that the need for labor induction, the occurrence of "prolonged and dysfunctional labour," excessive bleeding during delivery, and breech or other malpresentations of the baby increase with advancing maternal age. ${ }^{115}$ A Caesarean section may be necessary when there are problems associated with the placenta, such as placenta abruption or placenta previa, or when the mother is suffering from certain serious conditions like diabetes or high blood pressure. ${ }^{116}$ Although many Caesarean sections are performed with no complications, there are risks associated with this surgery. When compared with vaginal deliveries, studies

104. Dimes, Pregnancy After 35, supra note 69.

105. Id.

106. Id.

107. McCarthy, supra note 16.

108. Dimes, Pregnancy After 35, supra note 69.

109. Id.

110. Id.

111. McCarthy, supra note 16.

112. Mayo Clinic Staff, Placental Abruption, MaYoClINIC.COM, December 5, 2007, http://www.mayoclinic.com/health/placental-abruption/DS00623 (last visited Jan. 17, 2009).

113. Id.

114. Id.

115. Luke \& Brown, supra note 11 , at 1264.

116. March of Dimes, C-Section: Medical Reasons, July 2008, http://www.marchofdimes.com/pnhec/240_1031.asp (last visited Jan. 16, 2009) [hereinafter Dimes, $C$-Section]. 
have shown that when the baby is in normal position, the risk of complications and death of both the mother and her baby is twice as high when the baby is delivered via Caesarean section. ${ }^{117}$ Following a Caesarean section, women are at risk for increased bleeding, infection, bladder or bowel injuries, and blood clots. ${ }^{118}$ Although rare, death is also more likely to occur after a Caesarean section than a vaginal delivery. ${ }^{119}$ Further, women who have previously had a Caesarean section and later become pregnant have a higher risk of developing placenta accreta, a condition in which the placenta implants into the uterine wall much too deeply and firmly, or placenta previa. ${ }^{120}$ While screening of embryos for genetic abnormalities is currently available, as discussed above, this screening does not prevent, or even reduce, these other pregnancy-related risks.

\section{CurRent State of Regulation In the UNited States}

The use of ARTs and other infertility treatments remains largely unregulated, at either the state or the federal level. At the federal level, there currently exists only the Fertility Clinic Success Rate and Certification Act of 1992 ("FCSRCA"). ${ }^{121}$ FCSRCA was passed by Congress in 1992, and "requires each medical center in the United States that performs ART procedures to report data to CDC annually on every ART procedure initiated." 222 This data is then used to determine the pregnancy success rates of the medical centers in the United States. ${ }^{123}$ The FCSRCA also requires

the Secretary [of Health and Human Services] to develop a model program for the certification of embryo laboratories to be carried out by the states, to distribute a description of the certification program to government officials of each state, and to encourage such officials to assist the state in adopting the program. ${ }^{124}$

FCSRCA neither mentions the age of a woman when it comes to access to

117. C-section Raises Risk to Mother and Infant, ReUTERS, Oct. 31, 2007, http://www.reuters.com/article/healthNews/idUSSAT17412420071031 (last visited March 13, 2009).

118. Dimes, C-Section, supra note 116.

119. Id.

120. Id.

121. See Fertility Clinic Success Rate and Certification Act of 1992, 42 U.S.C.A. $\S$ 263a-1 et seq. (West 1992).

122. Wright et al., supra note 27.

123. Wright et al., supra note 27.

124. Sheri A. Jayson, Comment, "Loving Infertile Couple Seeks Woman Age 18-31 to Help Have Baby. \$6,500 Plus Expenses and a Gift": Should We Regulate the Use of Assisted Reproductive Technologies By Older Women?, 11 ALB. L.J. SCI. \& TECH. 287, 298 (2001). 
fertility treatments, nor does it require that states adopt a certification program.

Because the FCSRCA "does not require states to create or adopt a certification program,... [a]n individual state may choose to adopt such a program on a voluntary basis." 125 Unfortunately, state regulation is lacking, and instead, states largely choose to let the fertility industry regulate itself. $^{126}$ A study conducted in 2005 showed that, "[o]n average, [210 of the then 369 fertility clinics] turn away only [four percent] of potential customers each year." 27 Of the responding clinics, "[o]nly [twenty-eight percent] had formal policies on who [these clinics would] accept or deny."128 Not only do fertility clinics rarely enact formal policies, but the states may be hesitant to legislate in the area of ARTs due to the fact that

the relevant science is not easily understood, deference to physicians and the recognition that the practice of medicine has been largely self-regulating, the queasiness with which reproductive and sexual issues are discussed, the fear of trampling constitutionallyprotected rights and the value of individual choice, and the ever-present political ramifications that tie this issue to that of abortion and the conservative right. $^{129}$

For those states that do have legislation relating to access to infertility treatments, it is often aimed at insurance coverage. Currently, twelve states require insurers to provide insurance coverage for the treatment and diagnosis of infertility. ${ }^{130}$ These states include Arkansas, Connecticut, Hawaii, Illinois, Maryland, Massachusetts, Montana, New Jersey, New York, Ohio, Rhode Island, and West Virginia. ${ }^{131}$ Two other states, California and Texas, require that insurers at least offer coverage for the treatment of infertility. ${ }^{132}$ Many of these states' laws impose, or permit the imposition of, a maximum age limit on women covered, as well as other limitations. For example, Connecticut's statute provides that the "policy may ... limit such

125. Id.

126. Byers, supra note 65 .

127. Marilynn Marchione, Few fertility clinics have policies for deciding who to help get pregnant, survey shows, THE ASSOCIATED PRESS, Jan. 19, 2005, available at http://www.aegis.org/NEWS/AP/2005/AP050132.html (last visited Jan. 31, 2010).

128. Id.

129. Susan B. Apel, Access to Assisted Reproductive Technologies, 12 Mich. ST. U. L. J. MED. \& L. 33, 37 (2008) (citations omitted).

130. National Conference of State Legislatures, State Laws Related to Insurance Coverage for Infertility Treatment, http://www.ncsl.org/programs/health/50infert.htm (last visited March 13, 2009).

131. Id.

132. Id. 
coverage to an individual until the date of such individual's fortieth birthday." 133

While these states require or permit the imposition of a maximum age limit on women for insurance coverage purposes, they do not require fertility clinics to impose a similar age restriction on women seeking access to infertility treatments. Therefore, it is left up to each fertility clinic to determine whether to impose a maximum age limitation. Such self-regulation can lead to dangerous results for a post-menopausal woman willing to go to great lengths to have a child of her own. For example, such a woman faces exploitation in that a fertility specialist may not try to dissuade her from paying for and undergoing such a high-risk procedure where the likelihood of success is extremely low. Such a woman is at risk for exploitation by fertility specialists in that the specialist may permit her to pay for and undergo the a high-risk procedure when the likelihood of success is extremely low. ${ }^{134}$

\section{A. Indiana}

Indiana currently lacks legislation requiring insurers to cover fertility treatments for certain age groups, but there has been at least one attempt to regulate some aspects of the fertility industry. From 2005 to 2006, Indiana legislators introduced proposed legislation, which would in effect, "prohibit health care providers from offering and performing any medical procedure on an unmarried woman for the purpose of conception or procreation... [This bill] ... would have required that couples who seek assistance to become pregnant ... would have to be married to each other."135 While unmarried couples would be prohibited from utilizing infertility treatments in order to become pregnant, the bill made no references to a woman's age with regard to access. This bill also "required intended parents to seek an assessment from a licensed child placing agency before any ART services could begin." 136 While this bill was ultimately dropped, it

133. CONN. GEN. STAT. ANN. § 38a-536 (West 2007).

134. See The Ethics Committee of the American Society for Reproductive Medicine, Fertility treatment when the prognosis is very poor or futile, 82 FERTILITY \& STERILITY 806 (2004), available at http://www.asrm.org/Media/Ethics/futility.pdf (last visited Feb. 14, 2009) (discussing ethical recommendations for physicians facing maximum age limitation issues). The Ethics Committee considers as an example of "treatment plans likely to be futile are those in which couples try IVF treatments with their own gametes when the female partner has ovarian failure or is over 50 years of age ...." Id. at 807. In cases perceived to be "futile" or those with a "very low prognosis," the Ethics Committee recommends that physicians fully inform patients of this fact and "refuse to initiate or continue [fertility] treatment when they have a reasonable medical judgment that the given treatment option is futile...." Id. at 807-8.

135. Judith F. Daar, Accessing Reproductive Technologies: Invisible Barriers, Indelible Harms, 23 BERKELEY J. GENDER L. 18, 45 (2008).

136. Apel, supra note 129 , at 38 ; see IND. HEALTH FINANCE COMM., DRAFT 
has been Indiana's only proposed legislation relating to access to infertility treatments.

\section{B. Nongovernmental Organizations}

In the area of reproductive technology, there are two notable nongovernmental organizations that attempt to provide some guidance. These organizations are the American Society for Reproductive Medicine ("ASRM") and the Society for Assisted Reproductive Technology ("SART").

ASRM is a non-profit organization that promulgates "recommendations regarding quality control for IVF clinics."137 ASRM publishes ethical guidelines and recommendations, as well as information regarding recommended procedures; minimum standards to be used by fertility clinics; joint reports discussing current topics in the area written by ASRM in collaboration with other medical professionals; in addition to many other publications designed to educate its members and maintain a high standard of quality in the field. ${ }^{138}$ ASRM recommends, for example, that women who wish to donate eggs be between the ages of twenty-one and thirty-four. ${ }^{139}$ ASRM justifies its preference for egg donors to be younger than age thirtyfour by stating "that younger women typically respond favorably to ovulation induction, produce more eggs and high-quality embryos with high implantation and subsequent high pregnancy rates."140 Membership in ASRM is not mandatory, however, and compliance with the recommendations and guidelines is voluntary even for member fertility clinics. ${ }^{141}$ Because it is not required for members to follow ASRM's recommendations and guidelines, "no enforcement mechanisms are in place to ensure compliance."142 Thus, each clinic (or clinic administrator) can make the determination of how to maintain that particular clinic.

SART is an "organization of professionals dedicated to the practice of assisted reproductive technologies ... in the United States. [SART] includes over 392 member practices, representing over [eighty-five percent] of the ART clinics in [the United States]."143 Membership in SART is also voluntary. The stated mission of SART "is to set and help maintain the

(2005) (proposing additional section IC 31-9-2-9.5), available at http://www.in.gov/legislative/ interim/committee/prelim/HFCO04.pdf (last visited Jan. 17, 2009).

137. Byers, supra note 65.

138. See ASRM, Third Party Reproduction, supra note 3. Practice Committee Reports: Guidelines, Statements and Opinions of the ASRM Practice Committee, http://www.asrm.org/Media/Practice/practice.html (last visited Feb. 14, 2009).

139. ASRM, Third Party Reproduction, supra note 13.

140. Id. .

141. Byers, supra note 65.

142. Byers, supra note 65.

143. Society for Assisted Reproductive Technology, What is SART?, http:// www.sart.org/WhatIsSART.html (last visited Jan. 9, 2009) [hereinafter SART, What is SART?]. 
standards for ART." "144 In addition, SART compiles and presents the success rates of fertility treatments performed by clinics located in the United States. ${ }^{145}$ SART participates in creating guidelines and minimum standards of care to be used in each clinic, and in order to become a member of this organization, clinics must comply with these guidelines and standards. ${ }^{146}$ SART recommends that women seeking to utilize ARTs using their own eggs be under the age of forty-four. ${ }^{147}$ SART also recommends that women undergoing ARTs with the use of donor eggs be under the age of fifty. ${ }^{148}$ Therefore, both ASRM and SART show a preference for women utilizing ARTS to be under the age of fifty, and even younger in certain cases.

\section{FEDERAL REgUlation Is NEEDED IN THE UNITED STATES}

\section{A. Why Regulation is Needed}

The examples of advanced-age child birth discussed in the Introduction of this Note showcase the extreme ways in which infertility treatments can be put to use. The stories of these women represent the use of reproductive technologies for reasons other than those for which it was intended - to assist women of child-bearing age in reproduction. According to the CDC, women are considered "of reproductive age" from fifteen to forty-four years old. ${ }^{149}$ While the use of such technology can be successful in some women of advanced age, as illustrated in the previous examples, it does not follow that this technology should be used in such extreme ways. The reasons given by some of these women for choosing to undergo infertility treatments - a seventy-year-old mother and grandmother whose sole purpose was to have a son, ${ }^{150}$ or a sixty-year-old mother of children aged six to thirty-three who wished to have a biological playmate for her youngest son and to "remove the stigma" associated with advanced-age pregnan$\operatorname{cies}^{151}$ - are hardly justifications for such extreme and irresponsible uses of these infertility treatments. While the few women that continue to ovulate into their later years may chose to continue to have children, for whatever reasons, this should not be justification for the use of infertility treatments in post-menopausal women. There can be no measure of control over the women that naturally continue to ovulate and maintain their ability to bear children. The same, however, is not true for post-menopausal women who

144. Id.

145. See SART, What is SART?, supra note 143.

146. Id.

147. Society for Assisted Reproductive Technology, ART Candidates, http://www.sart.org/Guide_ARTCandidates.html (last visited Feb. 13, 1009).

148. Id.

149. Wright et al., supra note 27.

150. Caplan, supra note 8.

151. AP, N.J. woman, supra note 5. 
then choose to reach out to infertility treatments in an effort to conceive.

Uniform federal regulation in the area of assisted reproduction is needed. The current system, consisting of leaving the regulation of infertility treatments up to the states and the individual fertility clinics, has proved insufficient. So long as this system is in use, there will always be some fertility clinics that are willing to use ARTs in risky, extreme and radical ways, such as physicians permitting a seventy-year-old to engage in IVF for the sole purpose of having a son. The safety and well-being of the women and of the unborn children are at issue. The increased risks to the mother and child caused by an advanced-age pregnancy provide strong justifications for the imposition of a maximum age limit on women seeking access to infertility treatments. It is one thing for women who have suffered premature menopause, or for pre-menopausal women who, for genetic or other medical reasons, cannot conceive on their own to utilize infertility treatments to assist in becoming pregnant. It is quite another situation for women beyond the age of menopause to take advantage of such technology in an attempt to conceive a child.

Permitting a post-menopausal woman to use ARTs is both unethical and irresponsible of the acquiescing physician. For a post-menopausal woman to have a child is selfish, and it is also unnatural. Additionally, and perhaps most importantly, it is dangerous to both the woman and the unborn child. While there may be many healthy and active post-menopausal women, the statistics show that pregnancy alone is very risky for both the older woman and the child. Even a seventy-year-old woman considered to be active and healthy with an uneventful pregnancy is highly likely to leave her baby orphaned, as the average life expectancy as of 2006 is 77.7 years old. $^{152}$ Therefore, in the case of the seventy-year-old mother, her child will likely be orphaned at the age of seven or eight.

The case of Omkari Panwar, discussed above in Part I, exemplifies the selfish nature of post-menopausal women utilizing ARTs. The exploitation of fertility treatments in order to have a child of a certain sex is arguably both ethically and morally questionable at any age. But when the mother is seventy years old, as Panwar was, and her sole purpose in achieving a pregnancy is so she may have a boy, the utilization of ART by post-menopausal women is both self-serving and unjustifiable. A woman should not be permitted to expose a prospective child to the risk of Down syndrome or other chromosomal anomalies as high as 1 in 11 and 1 in 8 , respectively, for the sole purpose of having a child of a certain sex. ${ }^{153}$ In addition to these high risks to the child, a woman of such advanced age puts herself at great risk.

152. National Center for Health Statistics, U.S. Department of Health and Human Services, Centers for Disease Control and Prevention, Life Expectancy, http://www.cdc.gov/ nchs/fastats/lifexpec.htm (last visited Jan. 9, 2009).

153. McCarthy, supra note 16. 
For instance, older women are much more likely to suffer from gestational diabetes and pregnancy-induced hypertension, as well as many severe risks during the delivery. ${ }^{154}$ While cases such as those mentioned in this Note may be extreme examples, as long as no uniform regulation exists, there will always be physicians at fertility clinics willing to allow their patients to utilize ART in such controversial ways.

In the case of Frieda Birnbaum, also discussed above in Part I, Birnbaum's stated reasoning for wanting another child was so her son, age six at the time, "would have siblings closer to his age," as her other two children were much older. ${ }^{155}$ Birnbaum also stated as her reasoning for undergoing fertility treatments at the age of sixty that she "wanted to remove some of the stigma attached to older women giving birth." self and her unborn child through a high-risk pregnancy is self-serving, and it is unjustified by the sole reason of providing the mother's other children with a biological playmate close in age. Such behavior fails to take into account the best interests of the unborn child.

Another selfish aspect of such examples is that at a young age most of these children will be left with either parents that are very old or parents that are deceased. In Birnbaum's case, when her twins are just ten years old, she will be seventy years old. While Birnbaum may be in good health at the age of sixty, it is not as likely that she will maintain a healthy state at the age of seventy. Also, it will be very difficult for a seventy-year-old to take care of two ten-year-old children. Especially troubling are the cases such as Panwar's, as Panwar will be eighty years old when her twins are only ten years old. It is highly likely that Panwar's twins will be orphaned. In the event that these parents are still living, parents in their sixties, seventies, and older, will will likely be incapable of being as involved with the child as a younger parent would be. These older parents will not have the energy necessary to keep up with a small child every day.

It is unnatural for a post-menopausal woman to reproduce. Once a woman undergoes menopause, she is no longer capable of reproducing on her own. With the exception of women who suffer premature menopause, post-menopausal women should not then be permitted to utilize infertility treatments in an attempt to override Mother Nature's limit on the ability to bear children. Naturally, women's fertility begins to decline around the age of thirty, with a sharp decline occurring around the age of thirty-eight. ${ }^{157}$ This decline in fertility is accompanied by a decrease in egg quality. This appears to be nature's way of limiting a woman's ability to conceive as she ages, and at a certain point, on average around the age of fifty-one, women stop ovulating all together. Circumventing Mother Nature's limit on repro-

154. McCarthy, supra note 16.

155. AP, N.J. woman, supra note 5.

156. AP, N.J. woman, supra note 5.

157. See McCarthy, supra note 16. 
duction is risky and frequently leads to problems for the mother, the child, or both.

Other fields dealing with reproduction and infertility have set age limitations on women, and sometimes on both men and women. For example, many adoption agencies throughout the United States have set age limits on parents seeking to adopt. Such agencies justify age restrictions "on the grounds that [parents above a certain age] would not have been likely to produce such children themselves."158 Therefore, while some may argue that government regulation does not belong in such intimate and private decisions, age-related limitations on access already exist in similar areas. In any event, the United States Supreme Court has not held that a post-menopausal woman's right to access ARTs is a constitutionally protected fundamental interest.

Federal regulation imposing a maximum age beyond which a woman may no longer access infertility treatments is necessary. This maximum age limit should be set at the average age of menopause, age fifty-one. ${ }^{159}$ The age of menopause will undoubtedly change over the years, and the maximum age limit should change along with it. While some women may experience menopause at a later age (the range being, on average, age forty to fifty-five), ${ }^{160}$ the vast majority of women will not. For those women who do experience menopause at a later age, they would not be prevented from naturally conceiving a child. Given the high likelihood of complications and risks to both the mother and the child when women are forty-nine years old and older, and even as young as forty years old, the justifications for extending the maximum age limit to fifty-five or older are strongly outweighed by such risks.

Federal regulation of the fertility industry, as opposed to leaving it to the individual states to regulate, would create a uniform rule that all fertility clinics throughout the United States would be required to follow. In addition, cryogenic technology allows a woman to freeze her eggs or embryos before reaching the cut-off age of fifty-one. In such cases, a fertility clinic shall not be permitted to then implant the thawed embryo, or to fertilize the thawed egg and implant it into a woman once she has reached the age of fifty-one.

Such age-related regulation is not taking away any right that women naturally would have otherwise, save the small percentage of women who will undergo menopause at an age later than fifty-one. In any event, women

158. Naomi D. Johnson, Note, Excess Embryos: Is Embryo Adoption a New Solution or a Temporary Fix?, 68 BROOK. L. REv. 853, 873 (2003) (quoting Elizabeth Bartholet, Family Bonds: Adoption and the Politics of Parenting 72 (1993)).

159. See OPINION No. 413, supra note 15 , at 1 .

160. See Centers for Disease Control and Prevention, Women's Reproductive Health: Menopause, http://www.cdc.gov/reproductivehealth//WomensRH/Menopause.htm (last visited Jan. 9, 2009). 
aged fifty years and older who have not yet undergone menopause only have five-tenths of a percent chance of conceiving. ${ }^{161}$ Post-menopausal women have biologically lost the ability to reproduce, and no longer can they use their own eggs but must instead use donated eggs or embryos. Additionally, as mentioned in Part I.B., only one percent of women as young as forty-four who decide to use their own eggs in undergoing ARTs will achieve a live birth. ${ }^{162}$ Therefore, restricting access to the ARTs by women fifty-one years of age and older does not rob the majority of women of a chance at conceiving a child that they would have had but for an unanticipated genetic condition, disease, or medical treatment.

\section{B. Substantive Due Process Framework}

The United States Supreme Court (the "Court") recognizes a fundamental right to determine whether to bear a child. ${ }^{163}$ as included in the right to privacy. To date, the Court has not, however, recognized access to infertility treatments as a constitutionally protected fundamental right. It has been suggested that "a fairly strong doctrinal case can be made for recognizing access to IVF as a protected fundamental right [, and this] right ... would ... likely be framed ... as part and parcel of [the right to reproductive decision-making]." 164 While it has been argued that infertility treatments may be an infertile individual's only hope of conceiving a child, ${ }^{165}$ a post-menopausal woman is not considered to be "infertile." Therefore, the Court may not view the right of access to infertility treatments by a post-menopausal woman the same as the right of access to infertility treatments by an "infertile" woman.

\section{Different Levels of Review}

The Court utilizes three standards of review when called upon to decide a challenge to a statute or other regulation based upon substantive due process grounds. These standards of review include: strict scrutiny review, intermediate review, and rational basis review. These three standards differ in the amount of deference given to the government's interests advanced in

161. Jayson, supra note 124 , at 303.

162. CDC, 2006 ART Report, supra note 26, at 27.

163. Skinner v. State of Oklahoma ex rel. Williamson, 316 U.S. 535, 541 (1942).

164. Note, Assessing the Viability of a Substantive Due Process Right to In Vitro Fertilization, 118 HARV. L. REV. 2792, 2805-06 (2005) [hereinafter Assessing the Viability]. This Note provides an in-depth discussion of substantive due process issues as they relate to access to IVF, broadly.

165. Id. at 2805.

166. See supra Part I.A. As discussed in Part I.A., the term "infertile" is used to describe women of normal childbearing age. National Institute of Child Health and Human Development, supra note 20. 
support of the statute or other regulation.

\section{a. Strict scrutiny}

In the event that access to fertility treatments is determined to be a fundamental right, a strict scrutiny standard of review may be used by the Court should such regulation is challenged. A strict scrutiny standard of review provides that "a regulation found to burden a constitutionally protected fundamental right will only be upheld if it is 'narrowly tailored to serve a compelling [governmental] interest.",'167 It is difficult for a statute or regulation to overcome strict scrutiny, as this standard is the least deferential to the government.

\section{b. Intermediate Scrutiny}

The Court will, however, sometimes apply an intermediate scrutiny standard of review when dealing with cases involving a fundamental right. ${ }^{168}$ As the name suggests, this level of review is less deferential than strict scrutiny but more deferential than rational basis review. According to the intermediate scrutiny standard of review, when a regulation "significantly interferes with the exercise of a fundamental right, it cannot be upheld unless it is supported by sufficiently important [governmental] interests and is closely tailored to effectuate those interests." $" 169$

\section{c. Rational Basis}

Rational basis standard of review is the most deferential to the government. Most statutes and regulations reviewed under this standard will be upheld. Rational basis review provides that the challenged regulation must bear a rational relation to a legitimate governmental interest. ${ }^{170}$

\section{d. Which Standard of Review Applies}

Which standard of review is applied by the Court in the event of a challenge to a regulation depends upon whether it is determined that a constitutionally protected fundamental right exists as to access to infertility treatments by post-menopausal women. It is difficult to predict a court's

167. Assessing the Viability, supra note 164, at 2806 (citing Reno v. Flores, 507 U.S. 292, $302(1977))$.

168. Id. at 2807.

169. Assessing the Viability, supra note 164, at 2807 (citing Zablocki v. Redhail, 434 U.S. 374, $388(1978))$.

170. See, e.g., Washington v. Glucksberg, 521 U.S. 702 (1997) (applying the rational basis standard of review). 
determination on the specific issue of access to infertility treatments by post-menopausal women.

There appears to be a strong argument for recognizing a constitutionally protected fundamental interest in access to infertility treatments by the "infertile." post-menopausal woman, as opposed to an infertile woman. Therefore, while the Court is more likely to recognize a constitutionally protected fundamental right of infertile women to access most infertility treatments within their right to reproductive decision-making, it is less likely that the Court will conclude the same when it comes to post-menopausal women.

It is highly unlikely that the right of post-menopausal women to access infertility treatments is "'deeply rooted in this Nation's history or traditions," "172 which the Court has stated as a means of determining whether a fundamental right exists. Because post-menopausal women could not, until recently with the advent of infertility treatments, conceive, their right to access such infertility treatments would not be considered "deeply rooted in this Nation's history or traditions." While this argument appears to suggest that women of child-bearing age also lack a constitutionally protected fundamental right of access to infertility treatments due to the fact that access to such treatments is not "deeply rooted in this Nation's history or tradition," it may be that the Court will find such a right of access for these woman to be coextensive with another recognized fundamental right, such as the right to procreation. ${ }^{173}$ In that case, the right of access to infertility treatments itself would not need to be "deeply rooted in this Nation's history or traditions," because it would be considered part of a prior recognized fundamental right. Therefore, the fact that strong arguments and justifications exist against recognizing a constitutionally protected fundamental right of access to infertility treatments by post-menopausal women, this does not necessarily preclude recognition of such a right for women of child-bearing age.

If the Court makes the determination that a constitutionally protected fundamental right of access to infertility treatments by post-menopausal women exists, the Court would then need to determine whether to apply a strict scrutiny standard of review or an intermediate scrutiny standard of review. If, instead, the Court determines that a constitutionally protected fundamental right of access of infertility treatments by post-menopausal

171. See Assessing the Viability, supra note 164, at 2808 (concluding that, while difficult to predict the ultimate outcome, it is likely that the United States Supreme Court would recognize a fundamental right of access to IVF and would apply intermediate scrutiny to any regulation restricting access).

172. Id. at 2803; See also Washington v. Glucksberg, 521 U.S. 702 (1997) (setting out the test for determining substantive due process rights).

173. See Assessing the Viability, supra note 164, at 2803-04 (discussing the Glucksberg framework in determining whether a fundamental right exists as to access to IVF). 
women does not exist, then the court would use the rational basis standard of review.

Once the level of review has been determined, the Court will then look to the government's asserted interests in regulating access to infertility treatments and decide if those interests are related to and justify the restriction to the degree required by the chosen level of review. As mentioned above in Part IV.B.1.a., it is difficult for any regulation to pass a strict scrutiny standard of review, which requires that the regulation be narrowly tailored to serve a compelling governmental interest. Therefore, if strict scrutiny review is applied, it is likely that regulation restricting the access of post-menopausal women to infertility treatments will not be upheld, depending upon the Court's view of the government's interests and whether the regulation is narrowly tailored. If rational basis review is applied, it is highly likely such regulation will be upheld, so long as the asserted governmental interests are reasonable and are not arbitrary. It is more difficult to predict the outcome if intermediate scrutiny review is applied because it depends greatly upon the Court's balancing of both the private interests and the governmental interests at stake.

\section{Governmental Interests Advanced by Restricting Access to Infertility Treatments Based Upon Age}

The most important, and perhaps the most obvious, interest advanced by restricting access to infertility treatments by post-menopausal women is protecting the health of the woman and the child. As discussed throughout this Note, there are many substantial risks facing women of advanced age who decide to undergo infertility treatments. For example, older women over the age of forty are twice as likely to suffer from gestational diabetes as younger women, are much more likely to experience high blood pressure during pregnancy, and suffer an increased rate of delivery-related complications as a woman ages, including severe and potentially life-threatening hemorrhaging.

In addition to the risks facing older women, the unborn children are faced with significant risks. The unborn child faces a high likelihood of being born prematurely, which can lead to a variety of health problems, some of which are life-long. Furthermore, the rate of stillbirth doubles for women in their forties as compared to women in their twenties. Perhaps the most troublesome statistic is that at the age of forty-nine, a woman has a 1 in 11 chance of having a child afflicted with Down syndrome and a 1 in 8 chance of having a child born with some other chromosomal anomaly. ${ }^{174}$ Such risks coupled with the considerable decrease in the success of infertili-

174. See supra Part II. (discussing the risks to both the mother and the child associated with advanced-age pregnancies). 
ty treatments in women of advanced age, provide strong justifications for governmental interference in this area. The Court is likely to view such a governmental interest in protecting women and unborn children from such extreme risks as at least an important, if not a compelling, governmental interest. Additionally, "[ $\mathrm{t}] \mathrm{he}$ Court has traditionally accorded great deference to ... regulations based on public health concerns . . ."175

Another important governmental interest is protecting postmenopausal women from being taken advantage of by fertility specialists. ${ }^{176}$ Many women seeking the assistance of infertility treatments are desperate and willing to do and try anything to achieve their dreams of becoming mothers. This may be especially true with a woman past the age of menopause, who may have put off child-bearing for a number of reasons and for whom infertility treatments are now her only hope to achieve pregnancy. In such situations, these women are likely to be emotionally and mentally fragile and willing to believe that treatment will be successful in their case, no matter how unlikely. This situation creates the opportunity for exploitation of these women by physicians. Because no uniform regulation exists that is aimed at setting a maximum age limit on women, and because infertility treatments are extremely expensive, ${ }^{177}$ physicians may be inclined to provide such treatment even though the chances of success are incredibly low and the risks are high. ${ }^{178}$ As discussed previously in this Note, the rate of miscarriage for women over the age of forty can be as high as fifty per-

175. Assessing the Viability, supra note 164 , at 2810.

176. See Assessing the Viability, supra note 164, at 2810-11 (suggesting that "another strong state interest in regulating IVF is protecting the infertile from exploitation" regarding overall access to IVF).

177. See Jayson, supra note 124, at 328-30 (discussing the costs associated with ARTs). As of the year 2001, a single cycle of IVF cost between $\$ 8,000$ and $\$ 12,000$. Id. During that same time, artificial insemination cost approximately $\$ 111$ per visit and an additional $\$ 250$ for the semen specimen. Id. Medication used in connection with ART procedures cost approximately $\$ 1,300$ for an eight day supply, and ART involving the use of a frozen embryo cost around $\$ 1,000$. Id. Additionally, the use of a donated egg, which is a requirement for a post-menopausal woman seeking to conceive, would cost anywhere from $\$ 13,000$ to $\$ 25,000$ per attempt. Id. The costs of these procedures add up quickly, as many women, particularly older women will require more than one cycle.

178. See Judith F. Daar, Regulating Reproductive Technologies: Pancea or Paper Tiger?, 34 Hous. L. REV. 609 (1997)(discussing in Part II.A.3 informed consent issues surrounding the use of ART, including a discussion of the need for full disclosure of risks and chances of success, as well as the potential predatory practices of physicians). In her article, Daar argues that:

to the extent patients have shown a willingness to buy these [expensive] services ..., physicians have shown an equal desire to provide such services despite outcome data that suggests a low probability of success .... [P] hysicians have little or no incentive to counsel patients to stop treatment, because there may be a chance, albeit slight, that this patient will succeed.

Id. at 631 . 
cent. ${ }^{179}$ Even in the event that a post-menopausal woman is turned down at one clinic, she may simply go right to another clinic and find a physician willing to assist her in undergoing infertility treatments. ${ }^{180}$

For a post-menopausal woman who has found a willing physician, predatory practices continue when the physician allows the woman to continue infertility treatments after one or more failed attempts. ${ }^{181}$ These women will incur crushing debt and are not likely to see the intended result, such as a successful full-term pregnancy. What these women are more likely to experience, however, are the adverse risks associated with advancedage pregnancies.

Additionally, as discussed in Part III, some states permit insurance providers to impose maximum age limits on coverage for infertility treatments. Women over the age limit in these states are left to pay for their infertility treatments out-of-pocket. For a physician at a fertility clinic to then proceed to treat a post-menopausal woman, knowing she is incurring great expense, that she very likely cannot afford, that her chances of achieving a successful pregnancy are very low, and that her and her child's risks of severe complications are high, would be unethical. The government has a strong interest in protecting these women from such predatory practices.

\section{CONCLUSION}

In conclusion, the substantial likelihood of health risks to both women and children associated with advanced-age pregnancies, coupled with the potentially predatory actions of physicians justify the imposition of a maximum age limit on women seeking access to infertility treatments. The government has a strong interest in protecting these woman and their unborn children from the high risk of adverse health consequences associated with such advanced-age pregnancies. Furthermore, the government has a strong interest in protecting post-menopausal women from predatory practices of physicians willing to treat these women despite the high risks to the health of the woman and her child, the unlikelihood of a successful fullterm pregnancy, and the high cost of such treatments.

Should such regulation be imposed, a substantive due process challenge would likely arise. As discussed above in Part IV.B. of this Note, even if the Court finds that access to infertility treatments is a constitution-

179. Byers, supra note 65.

180. See The Ethics Committee of the American Society for Reproductive Medicine, Fertility treatment when the prognosis is very poor or futile, 82 FERTILITY \& STERILITY 806 (2004), available at http://www.asrm.org/Media/Ethics/futility.pdf (last visited Feb. 14, 2009).

181. Iliescu, whose story was discussed supra Part I. INTRODUCTION, had undergone nine years of unsuccessful fertility treatments before finally conceiving and giving birth to her daughter at the age of sixty-six. See AP, Romanian woman, supra note 1. 
ally protected fundamental right, it is unlikely that such a fundamental right would be found to exist as to post-menopausal women. If a fundamental right to access is found to exist even for post-menopausal women, the Court will apply either a strict scrutiny standard of review, or an intermediate scrutiny standard of review. In light of the strong interests advanced by regulation imposing a maximum age limit on access to infertility treatments by post-menopausal women, as discussed above in Part IV.B.2, it is likely that the Court will defer to such interests and uphold the limited regulation. The government should protect these interests of its citizens, and it should not be left up to individual fertility clinics to determine their own standards when such practice has proved to be inadequate. 